\title{
Um modelo espacial para análise e ensino de escolas de pensamento estratégico*
}

\author{
Rogério Quintella** \\ Sandro Cabral ***
}

SUMÁRIO: 1. Introdução; 2. Dimensões para análise de administração estratégica; 3. As escolas de pensamento de Mintzberg; 4. Considerações finais.

SUMMARY: 1. Introduction; 2. Strategic management analytical dimensions; 3. Mintzberg schools of thought; 4. Final remarks.

Palavras-chave: estratégia; escolas de pensamento estratégico; escolas de Mintzberg; ferramenta de análise; modelo espacial.

KEY WORDS: strategy; schools of strategic thought; Mintzberg schools; analysis tool; spatial model.

Este artigo propõe a construção de um modelo analítico das escolas de pensamento estratégico, observando a diversidade das correntes que compõem o campo da estratégia. Desta forma, contribui para uma melhor tipificação e identificação das distintas abordagens existentes, o que é bastante útil tanto para o ensino quanto para o exame das questões estratégicas. Com base na literatura, estabelece as dimensões de análise mais importantes e explicativas para descrever, estudar e ensinar os diferentes enfoques da administração estratégica. O resultado é um modelo

\footnotetext{
* Artigo recebido em ago. 2007 e aceito em nov. 2007.

** Doutor em gestão estratégica pela University of Brighton, professor da UFBA, autor de The strategic management of technology e vários textos sobre gestão estratégica, editor geral de periódicos da Anpad. Endereço: Escola de Administração da UFBA — Av. Reitor Miguel Calmon, s/n — CEP 40110-903, Salvador, BA, Brasil. E-mail: rhquintella@gmail.com.

$* * *$ Doutor em administração pela UFBA (em colaboração com a Univ. Paris 1-Sorbonne), pesquisador e professor visitante do Núcleo de Pós-Graduação em Administração da Universidade Federal da Bahia (NPGA-UFBA). Atualmente desenvolve pesquisas sobre as fronteiras das organizações públicas e privadas. Endereço: Escola de Administração da UFBA — Av. Reitor Miguel Calmon, s/n - CEP 40110-903, Salvador, BA, Brasil. E-mail: sandro.cabral@uol.com.br.
} 
dimensional adequado à comparação das escolas de pensamento contemporâneo sobre o tema. O arcabouço analítico desenvolvido é utilizado para o exame e a discussão do posicionamento das 10 diferentes escolas de pensamento identificadas por Mintzberg, Ahlstrand e Lampel em seu livro Safári de estratégia. De forma visual e didática, o modelo desenvolvido permite a observação das diferenças entre as escolas de pensamento estratégico, contribuindo para a tipificação dos diferentes autores da área. Por fim, o modelo facilita a elucidação da propalada polêmica entre dois expoentes do pensamento estratégico: Mintzberg e Ansoff.

\section{A spatial model for the analysis and teaching of schools of strategic thought}

This article proposes the construction of an analytical model of the schools of strategic thought taking into account the diversity of strategic currents. It therefore contributes to a better typification and identification of the different existing approaches, which is very useful both for teaching and examining strategic issues. Based on literature, it establishes the most important analytical and explanatory dimensions for describing, studying and teaching the different strategic management approaches. The result is a dimensional model that can compare the contemporary schools of thought. The analytical framework is used to examine and discuss the position of the 10 different schools of thought identified by Mintzberg, Ahlstrand and Lampel in their book Strategy safary. In a visual and didactic manner, this model shows the differences between the schools of strategic thought, aiding in the typification of the different authors. Finally the model helps to elucidate the widespread polemic between two strategic thought exponents: Mintzberg and Ansoff.

\section{Introdução}

Entre o final do ano de 1990 e meados de 1991, travou-se um intenso e influente debate entre dois dos mais importantes autores da área da estratégia nas organizações entre Henry Mintzberg e Igor Ansoff.

A última edição de 1990 do Strategic Management Journal trouxe um impactante artigo de Mintzberg cujo título eufêmico mencionava a intenção do autor de "reconsiderar as premissas básicas da administração estratégica". A edição de setembro de 1991 do mesmo periódico trouxe uma resposta indignada e aparentemente equivocada em defesa da chamada design school, por parte de Ansoff. Após 10 anos, o já consagrado Mintzberg, juntamente com Ahlstrand e Lampel, lançou uma obra seminal para os estudiosos da estratégia organizacional. No trabalho, os autores identificam e caracterizam 10 diferen- 
tes escolas de pensamento estratégico a partir de uma significativa revisão da literatura mundial sobre o tema.

Este artigo se propõe a conceber uma metaestrutura espacial para análise e ensino das disciplinas relacionadas a estratégias organizacionais. Além disso, é uma importante ferramenta para os estudiosos da área de estratégia interessados em classificar e tipificar as diversas contribuições teóricas que compõem o pensamento estratégico.

A primeira parte deste artigo é dedicada à discussão sobre quais são as dimensões de análise mais importantes e explicativas para descrever, estudar e ensinar os diferentes enfoques da literatura sobre administração estratégica. $O$ caminho para atingir esse primeiro objetivo tem como ponto de partida um modelo analítico espacial de três dimensões, criado pelo próprio Ansoff, em 1976, onde o autor considerava as dimensões do "processo", do "problema gerencial" e das "variáveis" para estudar as questões estratégicas das organizações. A partir do exame das contribuições de Ansoff (1976), aliadas às de Quintella (1993) e Quintella e Dias (1997), além de ponderações dos próprios autores do presente artigo, desenvolve-se um novo modelo dimensional de natureza mais eclética que o original proposto por Ansoff e simultaneamente mais adequado à comparação das escolas de pensamento contemporâneo sobre o tema.

A segunda parte do artigo é utilizada para análise e discussão do posicionamento das 10 diferentes escolas de pensamento identificadas por Mintzberg, Ahlstrand e Lampel (2000), à luz do modelo dimensional proposto. Realizam-se exercícios que permitem não somente a obtenção de resultados visuais e didáticos para interpretação e ensino das referidas escolas de pensamento estratégico, como também a tipificação dos trabalhos de diferentes autores da área, além da compreensão da polêmica de 1990/1991 mencionada na abertura deste artigo.

\section{Dimensões para análise de administração estratégica}

Numa visão crítica da discussão estratégico-empresarial, Tregoe e Zimmerman (1980) afirmam que a palavra estratégia tem sido empregada, na maior parte das vezes, de forma puramente acidental, tanto na literatura de negócios, quanto no ambiente de mercado: "de fato, ela tem assumido uma variedade de significados, alguns dos quais confundindo as dimensões do que e do como" (destaque nosso). Tregoe e Zimmerman (1980:16) definem estratégia como: "a diretriz das escolhas que determinam a natureza e a direção de uma organização". Em seu trabalho, esses autores procuram estabelecer a diferenciação entre 
"gestão operacional" e "gestão estratégica", relacionando a primeira à dimensão do "como" e a segunda à dimensão do "que".

A discussão de Tregoe e Zimmerman sobre suas supostas "dimensões da questão estratégica" merece ser contrastada com um importante texto de Drucker (1955), em que o autor propôs aos gestores dois questionamentos fundamentais: "o que é o nosso negócio; e o que ele deveria ser".

Obviamente, tais questões parecem trazer a discussão estratégica para a dimensão do "que". Não obstante, essa visão parece totalmente deslocada nos dias de hoje. Nunca os aspectos operacionais das organizações (dimensão do "como") estiveram tão próximos das questões estratégicas. Igualmente extemporânea, é a tentativa de discutir a questão estratégica das organizações com base em dimensões tão simples.

Uma visão muito mais completa das chamadas dimensões das questões estratégicas foi descrita por Ansoff em seu famoso livro de 1976, From strategic planning to strategic management, que tornou seu autor conhecido em todo o mundo como uma das maiores referências no campo da administração estratégica, na medida em que antecipou um paradigma que emergiria no "ambiente de mercado" muitos anos mais tarde. A análise de Ansoff do problema estratégico é baseada em três dimensões distintas: a primeira é descrita como processual, começando com planejamento e terminando com implementação. A segunda dimensão foi originalmente chamada problema gerencial e vai da configuração interna a ligações externas. Por último, Ansoff utilizou uma dimensão que denominou variáveis, incluindo aí três categorias: as técnico-econômico-informacionais, as psicossociológicas e as políticas.

O modelo de Ansoff (1976), apesar de apresentar algumas lacunas, pode ser útil aos propósitos deste artigo. A visão proporcionada pelo modelo pode facilitar a percepção da complexidade da questão, não apenas ao estudante, mas, também, àquele que conduz uma análise sistêmica de um problema real de administração estratégica em uma dada organização.

Embora modelos físicos e geométricos apresentem óbvias limitações quando confrontados com a complexidade, a sutileza e, por vezes, com a ambigüidade dos problemas e dos estudos organizacionais, parece interessante, minimamente sob a ótica didática, utilizar tais modelos. Com base nessa observação, as próximas seções deste artigo são dedicadas ao aprimoramento do modelo original de Ansoff para sua posterior aplicação nas 10 escolas do pensamento estratégico propostas por Mintzberg, Ahlstrand e Lampel (2000). 


\section{A dimensão processo}

Inicialmente, tomamos como exemplo a dimensão processo adotada por Ansoff, que a dividia em apenas duas etapas: planejamento e implementação. Podemos concluir dessa primeira observação que, para Ansoff, aparentemente toda estratégia deve ser planejada para que possa ser implementada. Apesar de ser essa a visão de muitos profissionais na academia e (principalmente) no ambiente de mercado, há que se considerar que para uma vasta gama de autores (a exemplo de Mintzberg), apesar de as estratégias poderem ser planejadas nas organizações, nem sempre tal fato ocorre, sendo as mesmas freqüentemente oriundas de outros processos de natureza menos deliberada (Mintzberg e Waters, 1985). Tais autores defendem a idéia de que as estratégias podem, eventualmente, emergir e, portanto, não depender necessariamente de um planejamento formal. Por essa razão, no modelo aqui proposto, utilizaremos o termo formação em lugar de planejamento. Entendemos que o segundo termo é mais amplo, englobando o primeiro e, portanto, sendo aplicável tanto aos casos de organizações com estratégias totalmente planejadas (deliberadas), quanto ao daquelas com processos primordialmente emergentes. Obviamente, o termo formação também contemplaria qualquer processo com características híbridas de deliberação e emergência de estratégias. ${ }^{1}$

Uma vez esclarecida a ampliação conceitual trazida pela primeira mudança sugerida para o modelo, é importante, agora, chamar a atenção e corrigir uma omissão aparentemente cometida por aquele autor. Em sua proposição, conforme mencionado, Ansoff divide o processo em apenas duas etapas, deixando passar despercebida a necessidade de uma etapa de processo anterior ao planejamento. Tal etapa, fundamental a qualquer ação gerencial sobre questões estratégicas (organizacionais ou não) é aquela onde ocorre a análise, o diagnóstico da organização e de seu ambiente. Em resposta a essa omissão do modelo propomos aqui a inserção de mais uma etapa ao mesmo. Devemos porém observar que os termos análise e diagnóstico anteriormente utilizados parecem bastante adequados aos processos formais de planejamento estratégico, embora não sejam, em princípio, propícios à descrição de processos mais emergentes de formação de estratégias.

Com essa preocupação em mente, propomos para o modelo, agora em construção, que se subdivida a dimensão processo, inicialmente proposta por

\footnotetext{
${ }^{1}$ É importante esclarecer que o conceito de estratégia adotado neste artigo é o mesmo da definição clássica de Mintzberg, ou seja, um padrão em um fluxo das decisões.
} 
Ansoff (1976), incluindo agora a etapa aqui denominada observação da realidade, doravante sinteticamente chamada de observação. Apesar de reconhecer que o termo observação não parece totalmente adequado, ele é mais abrangente que análise (embora menos formal que diagnóstico). Por outro lado, constatamos que, tanto no campo da pesquisa quanto no das práticas de mercado, a observação dos ambientes e contextos organizacionais é uma etapa preliminar a qualquer esforço de entendimento ou mesmo de síntese e planejamento de proposições e ações estratégicas. Assim, dentro dos moldes do modelo em elaboração temos, inicialmente, em sua dimensão processo, as etapas respectivas de observação, formação e implementação de estratégias, como observado na figura 1. Convém ressaltar que a divisão do modelo nessas três etapas tem um propósito ilustrativo, não devendo ser entendido que tais etapas tenham necessariamente que ocorrer de forma estanque e seqüencial.

Figura 1

Etapas da dimensão processo do modelo proposto

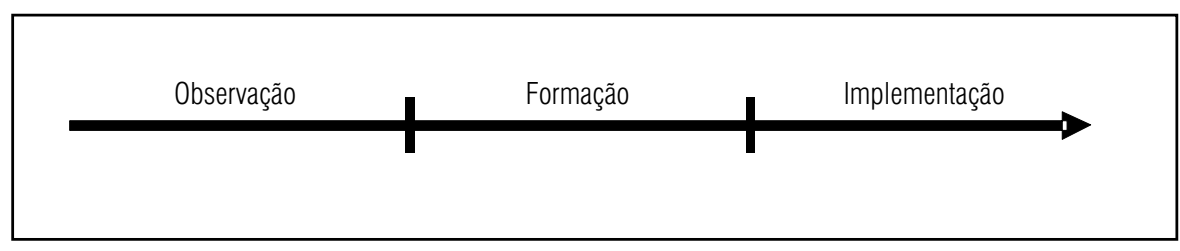

\section{A dimensão das variáveis}

Em seu trabalho original, Ansoff utilizou-se de uma dimensão de análise estratégica denominada variáveis, onde dividia e categorizava os tipos de variáveis mais pertinentes ao problema estratégico das organizações. Para ele, essas variáveis dividiam-se nas seguintes categorias: técnicas, psicológicas e políticas. A escolha e distribuição dessas categorias de variáveis, para quem conhece o trabalho de Igor Ansoff, são quase surpreendentes, uma vez que quase todo seu trabalho é focado na primeira das três categorias. Por outro lado, observamos que enquanto essa primeira categoria responde pelas variáveis de natureza mais tangível ou quantificável, as duas outras categorias acabam por compartilhar naturezas mais sutis, sendo tipicamente intangíveis.

Se o modelo aqui proposto torna-se mais detalhado na abordagem pela dimensão processo anteriormente discutida, ele torna-se simultaneamente mais simples e mais coerente ao propor a junção das variáveis psicológicas e políticas, resultando em apenas duas grandes categorias (tangível e intangível). 
Ao reconhecer, porém, a importância desses campos de menor tangibilidade, para a análise do comportamento estratégico das organizações, não se pode olvidar das dimensões sociológicas e institucionais, ${ }^{2}$ na medida em que elas apresentam impactos relevantes na conformação das estratégias e, por conseqüência, na determinação dos resultados. Nesse sentido, Granovetter (1985) argumenta que, em sociedades modernas as decisões econômicas estão imersas em estruturas de relações sociais institucionalizadas. Possuindo um papel de condicionar as condutas dos agentes, por meio de regras formais, leis, tabus ou códigos de conduta, as instituições podem potencializar ou mitigar, dependendo da maneira como estão configuradas tais redes de relacionamentos, representando forte influência, por exemplo, em processos emergentes de formulação estratégica, a serem debatidos nas próximas seções.

Feitas essas considerações, propomos aqui incorporar todos esses campos em uma única parte, intangível, da dimensão variáveis, denominando-a variáveis psicológicas, sociológicas e políticas.

Por outro lado, ainda na dimensão variáveis, entendemos que sua divisão em apenas duas partes demanda uma conceituação mais abrangente daquilo que Ansoff denominou simplesmente variáveis técnicas, tratando-as, então, como variáveis técnicas, econômicas e informacionais. A adição das dimensões informacionais, negligenciadas por Ansoff à época, é importante em função da relevância de aspectos relacionados à qualidade, à consistência, à disponibilidade e ao uso das informações no processo de tomada de decisão e formulação estratégica. O resultado dessa discussão é ilustrado na figura 2.

\section{Figura 2}

\section{A dimensão variáveis do modelo proposto}

\begin{tabular}{|c|c|}
\hline Técnicas, econômicas & Psicológicas, sociológicas \\
\hline e informacionais & e políticas \\
\hline
\end{tabular}

\section{A dimensão do problema gerencial ou da sua centralidade}

Ansoff, em seu texto de 1976, utilizou uma terceira dimensão para modelar a "questão estratégica das organizações". Esse último eixo foi por ele denomina-

\footnotetext{
${ }^{2}$ Doravante denominadas apenas variáveis sociológicas, para fins de simplificação.
} 
do problema gerencial, dividindo-se em duas partes complementares: a interna à organização e a externa. Sua escolha parece coerente com sua visão acerca das estratégias organizacionais. Naquele momento, os trabalhos do autor traduziam a idéia de que apenas aquilo que é relativo às interfaces de uma organização com seu ambiente (econômico, social, tecnológico, político etc.) é relacionado à administração estratégica. Para Ansoff (1965:5) "estratégico é tudo que relaciona a organização com seu ambiente".

Como o propósito deste artigo é construir um modelo adequado à tarefa de analisar e, simultaneamente, facilitar o estudo (e o ensino) de todas as escolas de pensamento estratégico (entre elas as descritas por Mintzberg 24 anos após o texto original de Ansoff), torna-se necessário expandir, flexibilizar e tornar mais versátil a dimensão do problema gerencial. Devemos observar ainda que o paradigma contemporâneo da administração estratégica envolve a idéia central de que toda a gestão deve ser estratégica. Ou seja, de que mesmo a gestão da produção deve ser conduzida de forma sincrônica às estratégias competitivas e corporativas de uma organização, caracterizando a administração estratégica da produção. ${ }^{3}$

Coerentemente com os propósitos do artigo e com os preceitos do paradigma da administração (ou gestão) estratégica, propomos uma ressignificação desse eixo do modelo, passando a entendê-lo não mais como aquele referente às fronteiras da organização, mas sim à centralidade dos fenômenos abordados (os problemas gerenciais). Assim, a nova dimensão do modelo passa a ser dividida em três categorias: centralidade inferior, centralidade intermediária e centralidade superior. ${ }^{4}$

Para melhor explicar a ressignificação aqui buscada, podemos exemplificar como centralidade superior (maior centralidade) a parcela do eixo por Ansoff denominada interna à organização e como de centralidade inferior (menor centralidade) o que aquele autor chamava de externo à organização. A ressignificação proposta permite o surgimento de uma categoria intermediária: a centralidade intermediária, que flexibiliza mais o modelo, como ficará evidente adiante. A dimensão (ou eixo) da centralidade traz uma outra possibilidade de flexibilização (e maior potencialidade ao modelo), já que a mesma pode ser percebida e utilizada sob duas distintas óticas:

\footnotetext{
${ }^{3}$ Para mais detalhes sobre esse ponto ver Skinner (1969).

${ }^{4} \mathrm{O}$ termo centralidade não é aqui usado em um sentido geométrico, mas sim com um sentido de abrangência ou de área de cobertura. Assim, centralidade superior significaria um foco mais fechado, abrangendo apenas um indivíduo. Por sua vez, uma centralidade inferior representa um foco mais aberto, abrangendo a sociedade de forma mais ampla.
} 
- a primeira, seria a visão macro (pode ser explicada como um zoom out da figura 3a). Nesse caso os adjetivos (inferior, intermediário e superior) seriam aplicados, respectivamente, à sociedade em que se insere uma organização, à organização propriamente dita e, por fim, aos indivíduos que compõem a organização;

v a segunda ótica é a da visão micro, onde os adjetivos da centralidade (inferior, intermediário e superior) referem-se às partes internas de uma organização, correspondendo, respectivamente, às esferas dos colaboradores, dos gerentes (de níveis hierárquicos intermediários) e a dos gerentes superiores ou direção (figura $3 \mathrm{~b}$ ). Dado esse enfoque, dizemos que a figura adiante é vista com zoom in.

Figura $3 a$

A dimensão centralidade (vista com zoom out)

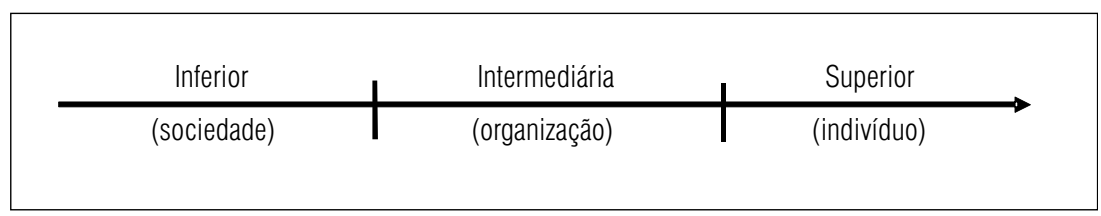

Figura $3 b$

A dimensão centralidade (vista com zoom in)

\begin{tabular}{|c|c|c|}
\hline Inferior & Intermediária & Superior \\
\hline (colaboradores) & (gerência) & (direção) \\
\hline
\end{tabular}

Essas exposições permitem a inclusão das três dimensões: processo, variáveis e centralidade, dentro de uma perspectiva unificada e inter-relacionada. A figura 4 ilustra a síntese do modelo desenvolvido para as análises das escolas estratégicas em um formato tridimensional. O modelo espacial facilita a visualização das influências de cada uma das dimensões presentes no processo de formulação das estratégias em cada uma das escolas de pensamento estratégico. Na próxima seção o modelo é apresentado à luz da classificação de Mintzberg e colaboradores (2000). 
Novo modelo do espaço analítico das questões estratégicas

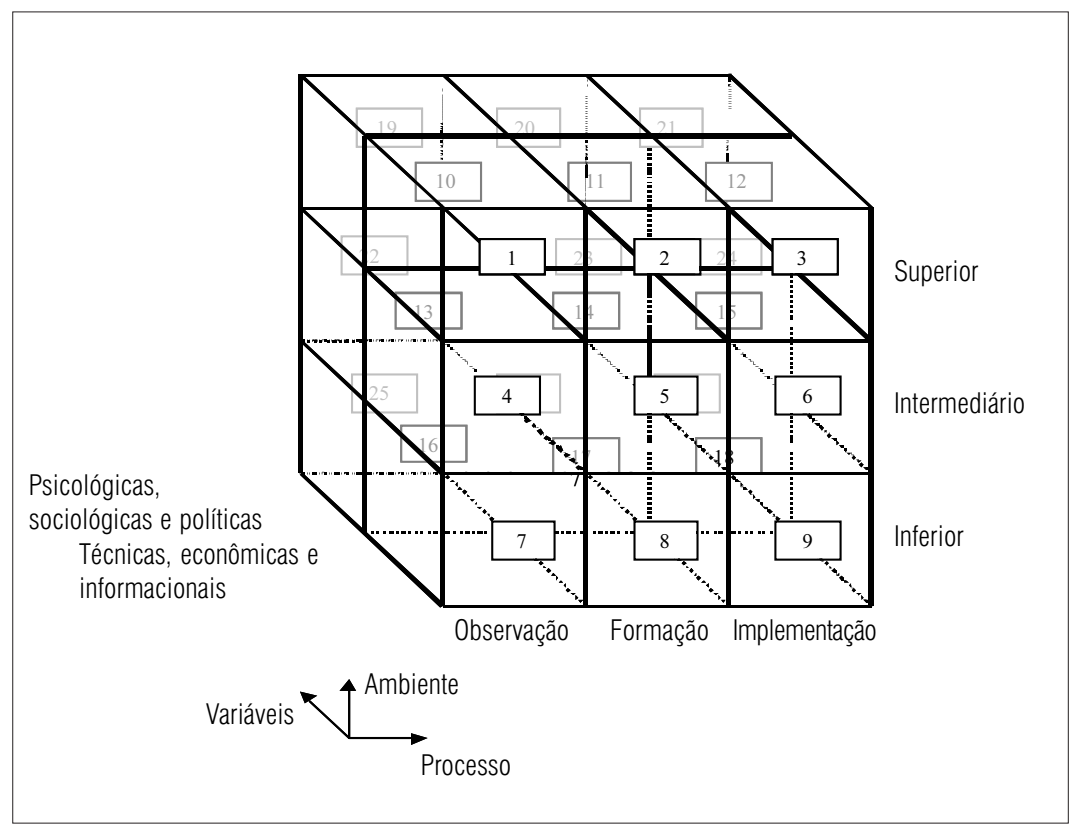

\section{As escolas de pensamento de Mintzberg}

Mintzberg, Ahlstrand e Lampel (2000) criaram uma tipologia profunda e detalhada dos distintos aspectos da administração estratégica, resultando na elaboração de uma das mais recentes e, segundo Vasconcelos (2001), mais ambiciosas classificações de estratégia já realizadas. Baseada em cerca de 2 mil publicações na área, essa metateoria tornou-se amplamente conhecida e reconhecida entre as comunidades acadêmica e profissional de mercado, transformando a obra em um best-seller da área. O resultado daquele estudo é uma grade de classificação que agrupa a produção técnica e científica da área ao longo de 40 anos, em 10 escolas de pensamento, caracterizadas conforme suas idéias centrais de forma cronológica aproximada. Cabe ressaltar que as hachuras mais escuras representam muito foco (ou atenção) da escola sobre a dimensão (ou suas partes), ao passo que o sombreamento mais claro indica pouco foco. Analogamente, as hachuras em tom acinzentado sinalizam relativa influência da escola de pensamento estratégico sobre a dimensão correlata. Escola do design 
Para a escola do design, o principal papel do gestor é analítico, cabendo ao pensamento preceder a ação para enfrentar com competência a necessidade de entender os ambientes e relacionar os pontos fortes e fracos da organização com suas ameaças e oportunidades, para assim estabelecer a estratégia a ser seguida. Por outro lado, a escola do design aborda também, embora com menor clareza e ênfase, os valores do gestor e sua responsabilidade social como influentes na escolha de tal estratégia. Segundo essa escola, a concepção de estratégia deve trazer simplicidade às organizações, entre outras razões, por ser a responsabilidade do controle e formulação de uma só mente, a do executivo principal.

Para essa escola, a estratégia é única e seu processo de desenvolvimento um ato primordialmente criativo. Nessa concepção, tal processo de formulação da estratégia só estaria completo quando desenvolvido de forma explícita e única, simples, embora tipicamente inflexível e restrita.

A escola faz clara distinção entre pensamento e ação, ou seja, um ator estrategista formula e outro(s) implementa(m), remetendo à idéia de separação entre pensar e agir da administração clássica e contribuindo, assim, para o distanciamento do processo de formulação estratégica da realidade. Entre os autores alinhados com essa vertente está Selznick (1957). A figura 5 ilustra a valorização da centralidade superior no pensamento estratégico da escola do design.

\section{Figura 5}

\section{Aplicação do modelo à escola do design}

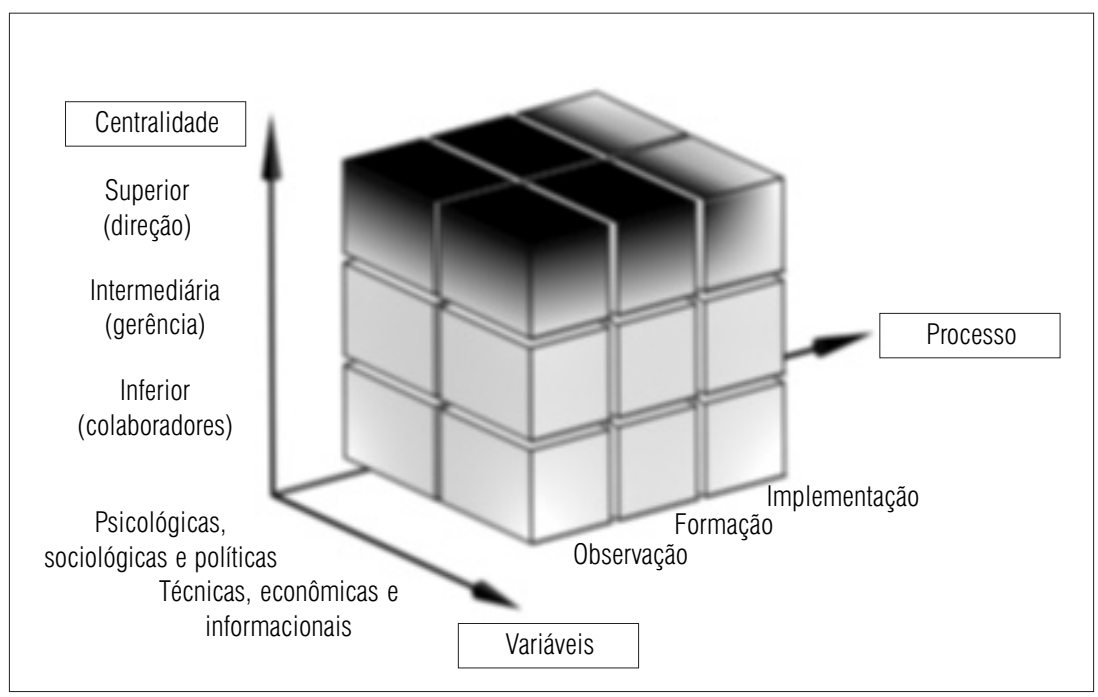




\section{Escola do planejamento}

Segundo Mintzberg, Ahlstrand e Lampel (2000), a escola do planejamento nasceu na mesma época que a escola do design. Sua literatura contém várias idéias enraizadas no modelo básico da primeira escola.

No planejamento, assim como no design, o executivo principal é quem detém o poder sobre as decisões e planos estratégicos, embora, na prática, deva aprovar e não mais propriamente conceber tais planos. Nessa escola, os planejadores profissionais são os principais atores do processo. As estratégias saem prontas desse processo, devendo também ser explicitadas para que possam ser implementadas com atenção a objetivos, orçamentos, programas e planos operacionais (apropriados ao seu lema: prever e preparar). Aqui, o planejamento passa a ser muito fortemente associado à idéia de controle, principalmente devido à formalidade de sua elaboração e à mecanização do processo.

As premissas dessa escola passam pelo aspecto tecnicista do planejamento. Suas estratégias são essencialmente deliberadas e o sucesso deverá ser decorrente de sua implementação controlada e livre de surpresas. Assim, essa escola parece concentrar-se principalmente nos espaços ilustrados na figura 6 , onde se observa a pouca valorização conferida às variáveis intangíveis e a discreta menção à implementação. Vemos também a dinâmica de descentralização de decisões na medida em que se caminha ao longo do eixo do processo. Ansoff (1965) notabiliza-se como um dos principais expoentes dessa escola, cuja concepção ainda influencia as ações de muitos executivos e consultores.

\section{Figura 6}

\section{Aplicação do modelo à escola do planejamento}

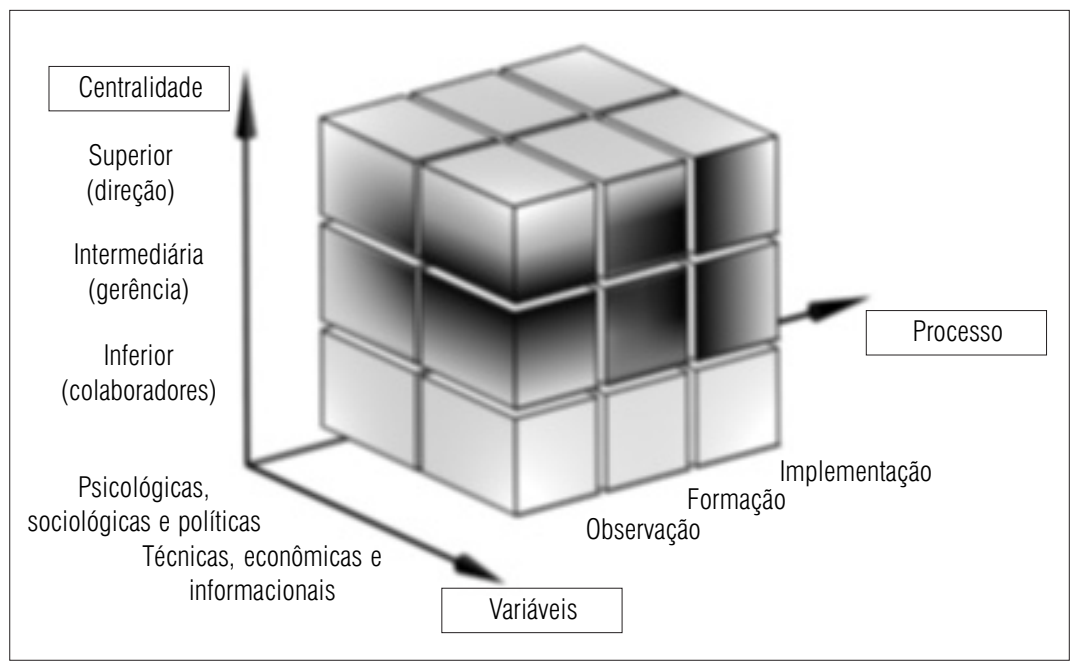




\section{Escola do posicionamento}

Nessa terceira escola, a formulação da estratégia continua como um processo controlado, formal e, portanto, consciente, produzindo estratégias deliberadas totalmente desenvolvidas, que devem ser explicitadas antes de serem implementadas. Como nas escolas anteriores, seu foco está na observação e formação no que tange à sua centralidade (baseado na seleção de posições estratégicas genéricas). A escola tipicamente ignora a etapa de implementação das estratégias.

Como no planejamento e no design, o executivo principal é o estrategista. No entanto, o grau de importância do planejador foi elevado, embora, segundo os autores, ele tenha se tornado fundamentalmente um analista que seleciona e recomenda as estratégias ótimas aos gerentes. Essa observação explica o destaque dado na figura 7 , na parte superior do nível gerencial e sua discreta abordagem sobre o papel do nível superior. Um dos autores emblemáticos dessa escola é Michael Porter.

Apesar da abordagem dessa escola ser orientada para o quantificável, em detrimento ao social e político, Porter (1980), mesmo sem usar a palavra política, faz alusão em seus trabalhos a manobras dessa natureza. Possivelmente, com base nessa observação, podemos dizer que essa é a concessão da escola às variáveis psicológicas, sociológicas e principalmente políticas, explicando o discreto preenchimento desse espaço na figura 7.

\section{Figura 7}

\section{Aplicação do modelo à escola do posicionamento}

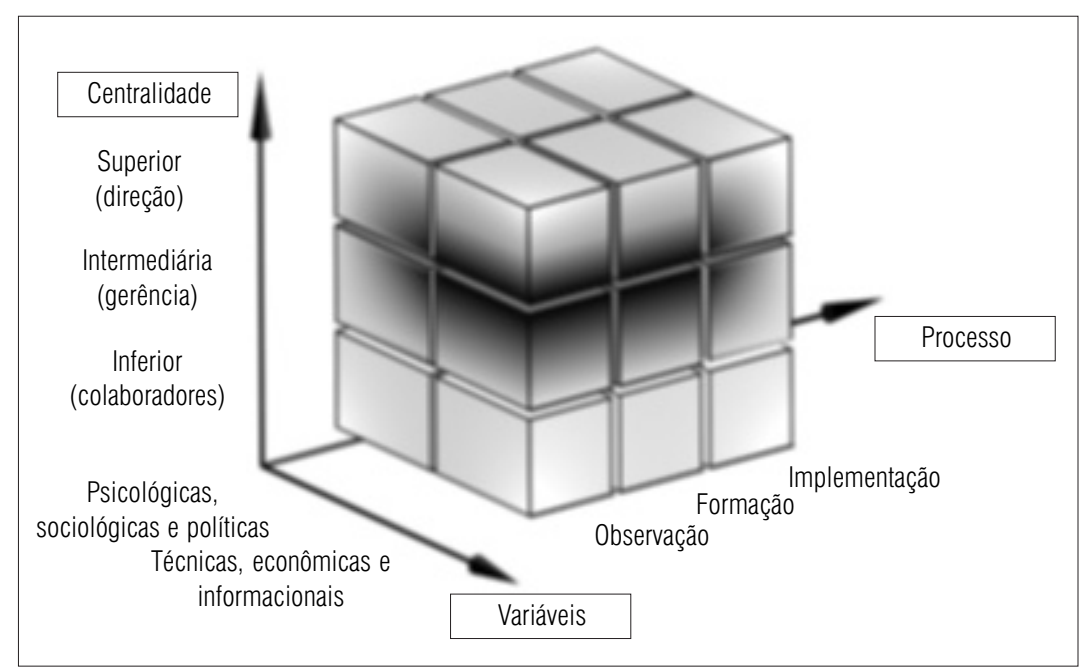




\section{Escola empreendedora}

Essa escola, assim como a escola do posicionamento, tem origem em alguns estudos de economia, nesse caso, porém, naqueles onde o empreendedor tem papel proeminente (Schumpeter, 1984). Diferentemente de todas as escolas anteriores, a escola empreendedora tem natureza descritiva e não prescritiva. Os autores que formam a escola buscam compreender o processo de formação de estratégia na medida em que ele se manifesta nas organizações (figura 8).

Novamente, o processo é focado em um único líder, porém o entendimento da estratégia como perspectiva, adotada nessa escola (conceito de visão), traz o foco de seus componentes para a representação mental da estratégia (provinda da natureza visionária do líder). É essa característica que daria ao líder empreendedor um senso de direção de longo prazo, uma perspectiva de futuro da organização. O líder promoveria a visão de forma decidida, mantendo o controle pessoal da sua implementação (o que não é muito explorado) dando-lhe, como conseqüência, um caráter mais flexível.

Essa escola, também de forma distinta às anteriores, enfatiza variáveis não tangíveis, tais como a intuição, a sabedoria, a experiência: a idiossincrasia humana. De tal maneira o processo estratégico passa a ser visto como semiconsciente. Aqui, a estratégia é vista como deliberada no que tange às suas linhas mais amplas (seu senso de direção, conferido pelo empreendedor visio-

\section{Figura 8}

\section{Aplicação do modelo à escola empreendedora}

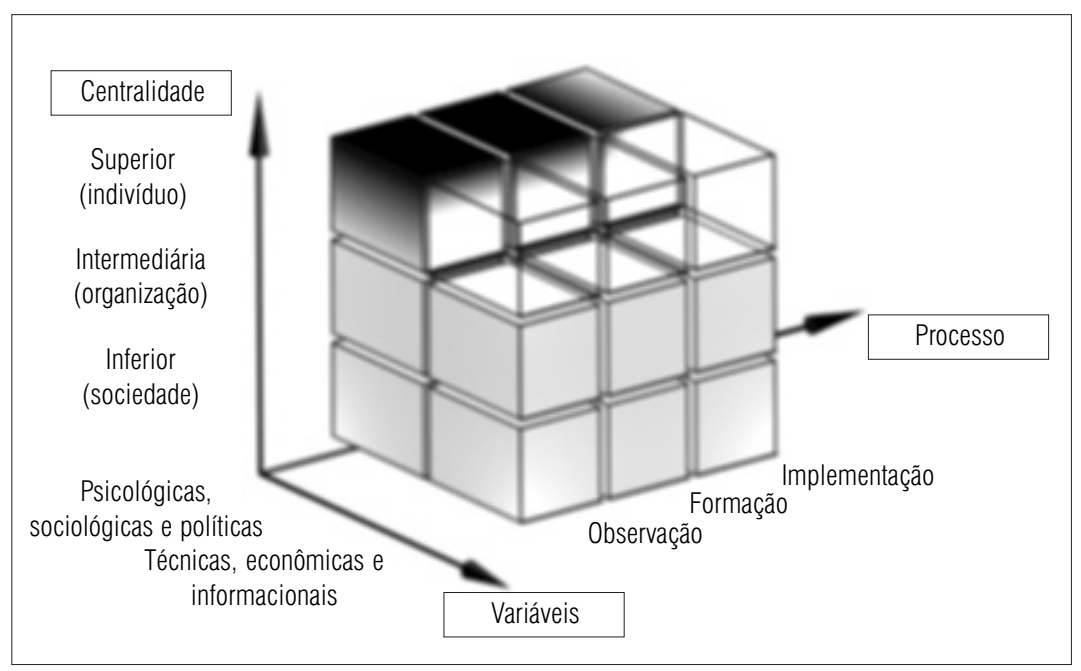


nário), porém como emergente (às vezes deliberadamente emergente) em seus detalhes e desdobramento.

O processo visionário do líder é centrado no indivíduo de nível hierárquico mais elevado da organização e foca principalmente nas etapas de percepção ou observação da realidade, formação da estratégia e discretamente na implementação. Parece, portanto, encaixar-se nos espaços da figura 8.

\section{Escola da cognição}

A escola cognitiva procura entender o funcionamento do cérebro humano para entender como, a partir da percepção (observação) da realidade, formam-se as estratégias na mente do estrategista. Assim, podemos reconhecer o foco dessa escola, não nas estratégias em si, mas em seu processo de derivação da realidade, percebida no âmbito da psicologia cognitiva.

Para os autores dessa escola os estrategistas são autodidatas que desenvolvem sua estrutura de conhecimento e seus processos de pensamento por experiência direta. A experiência forma o saber que, por sua vez, determina suas decisões e ações. A formação da estratégia é considerada um processo de cognição, que pode ocorrer de duas maneiras. A primeira, seria um processo individual de formação da visão - a cognição como recriação do mundo. Essa abordagem é característica da chamada ala objetiva da escola. A segunda, envolve um processo de maior interatividade, um processo coletivo de visão. É a abordagem da ala subjetiva da escola, onde a cognição é criadora do mundo subjetivo dos estrategistas. Aqui as estratégias podem emergir como uma perspectiva na forma de conceitos emoldurados de uma realidade complexa.

Para a escola da cognição, as estruturas de conhecimento e raciocínio do estrategista (nível do indivíduo no eixo da centralidade, na figura 9) são formadas principalmente pela experiência direta. Logo, ela se preocupa com a experiência decorrente da vida do gestor e em como as suas interpretações e intuições (tipicamente relacionadas às variáveis intangíveis, psicológicas e sociológicas) afetam as estratégias organizacionais. Segundo essa escola, cabe ao gestor a responsabilidade de comunicar a sua visão de mundo e transformála em uma realidade coletiva. Reconhecemos que os atores são racionais, embora limitadamente (Simon, 1947). A excessiva abordagem sobre o indivíduo nos processos de formulação estratégica e tomada de decisão vem recentemente sendo explorada pelos adeptos da neuroeconomics. O prêmio Nobel de Economia conferido a Vernon Smith em 2003 representa o reconhecimento da importância das condições mentais no processo de escolha. 
Figura 9

Aplicação do modelo à escola cognitiva

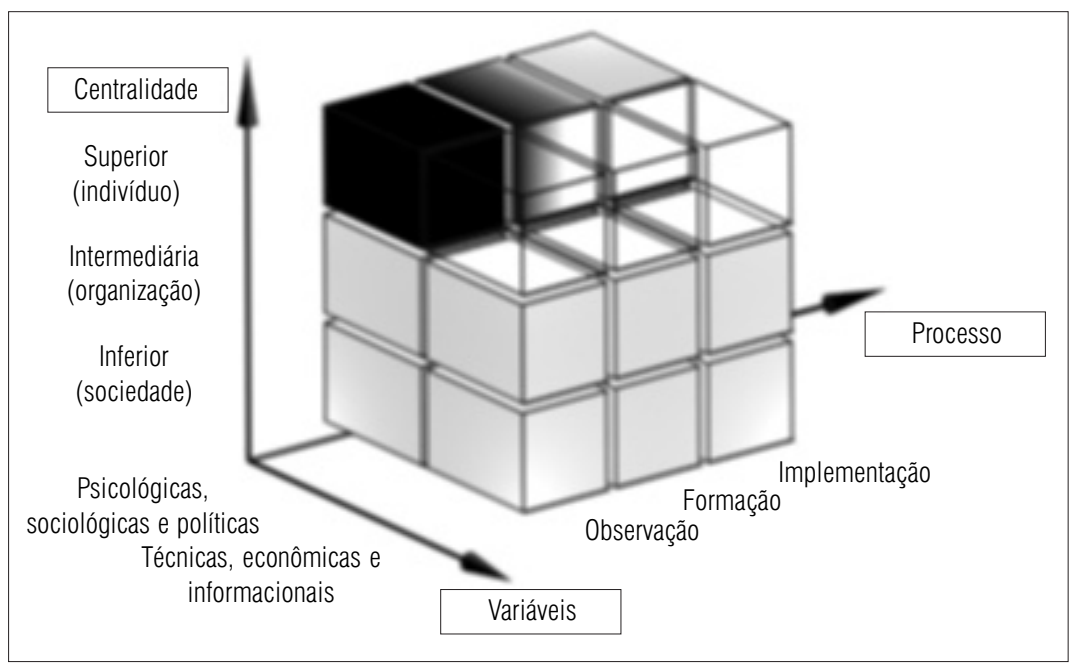

\section{Escola do aprendizado}

De acordo com essa escola, as estratégias emergem quando os atores, atuando individualmente (centralidade superior ilustrada na figura 10) ou na maioria das vezes coletivamente (centralidade intermediária), aprendem sobre uma situação, desenvolvendo a capacidade de sua organização em lidar com ela.

Suas premissas passam pelo aprendizado coletivo, e emergente de forma deliberada, em que os atores são comprometidos com os resultados globais. Os padrões aqui emergentes podem, e devem, ser internalizados à estratégia formal.

Segundo a abordagem dessa escola, o gerenciamento eficiente significa a capacidade de manter a aprendizagem ao mesmo tempo que se equilibram mudanças (implementação de estratégias no eixo de processo, na figura 10) com continuidade, sabendo o que e quando mudar. Tal balanceamento se deve ao fato de que o aprendizado (baseado principalmente no terço da observação do eixo de processo) deve influenciar a formação de estratégias organizacionais mais complexas, assim, entendemos que a escola cobre todo o eixo de processo.

Devido à natureza complexa e imprevisível do ambiente de uma organização, o controle deliberado se torna impraticável. Assim, a formação de estratégias necessita assumir a forma de um processo de aprendizado no qual formulação e implementação se confundem. Nessa escola, o papel da lideran- 
ça não é o de planejar estratégias, mas sim o de conduzir o processo de aprendizado, o que não acontece na escola cognitiva mencionada anteriormente. Cyert e March (1963) e Prahalad e Hamel (1990) são alguns dos autores inseridos nessa abordagem.

\section{Aplicação do modelo à escola do aprendizado}

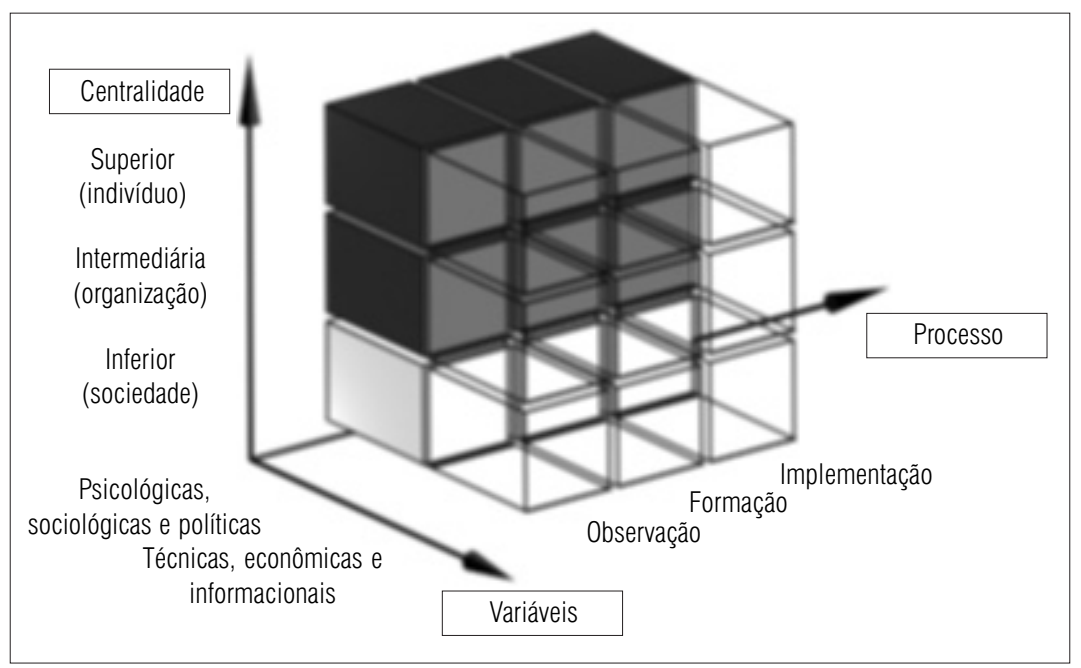

\section{Escola do poder}

A escola do poder explora a formação de estratégias como um processo de negociação e barganha, como um processo de influência, enfatizando o uso de poder e política (variáveis intangíveis, na figura 11) em seu processo. Essa escola considera a variável política um sinônimo de uso do poder, porém não de maneira puramente econômica. Decorre daí que as estratégias genéricas são oriundas de processos políticos.

Existem duas vertentes distintas nessa escola que consideram a relação de poder e política em amplitudes diferenciadas. A primeira é a vertente do poder micro, que aborda tais relações sob a perspectiva dos indivíduos e grupos internos à organização. Essa vertente considera as relações políticas e de poder concentradas principalmente nos níveis diretivos das organizações e nas fases de análise (observação) e formação (planejamento) das estratégias. O nível gerencial intermediário seria maior nas fases de planejamento e imple- 
mentação das estratégias. O trabalho de Allison (1971) ao analisar a crise dos mísseis entre Cuba e EUA tipifica o pensamento dos representantes do enfoque micro.

Figura 11

\section{Aplicação do modelo à escola do poder: enfoques micro e macro}

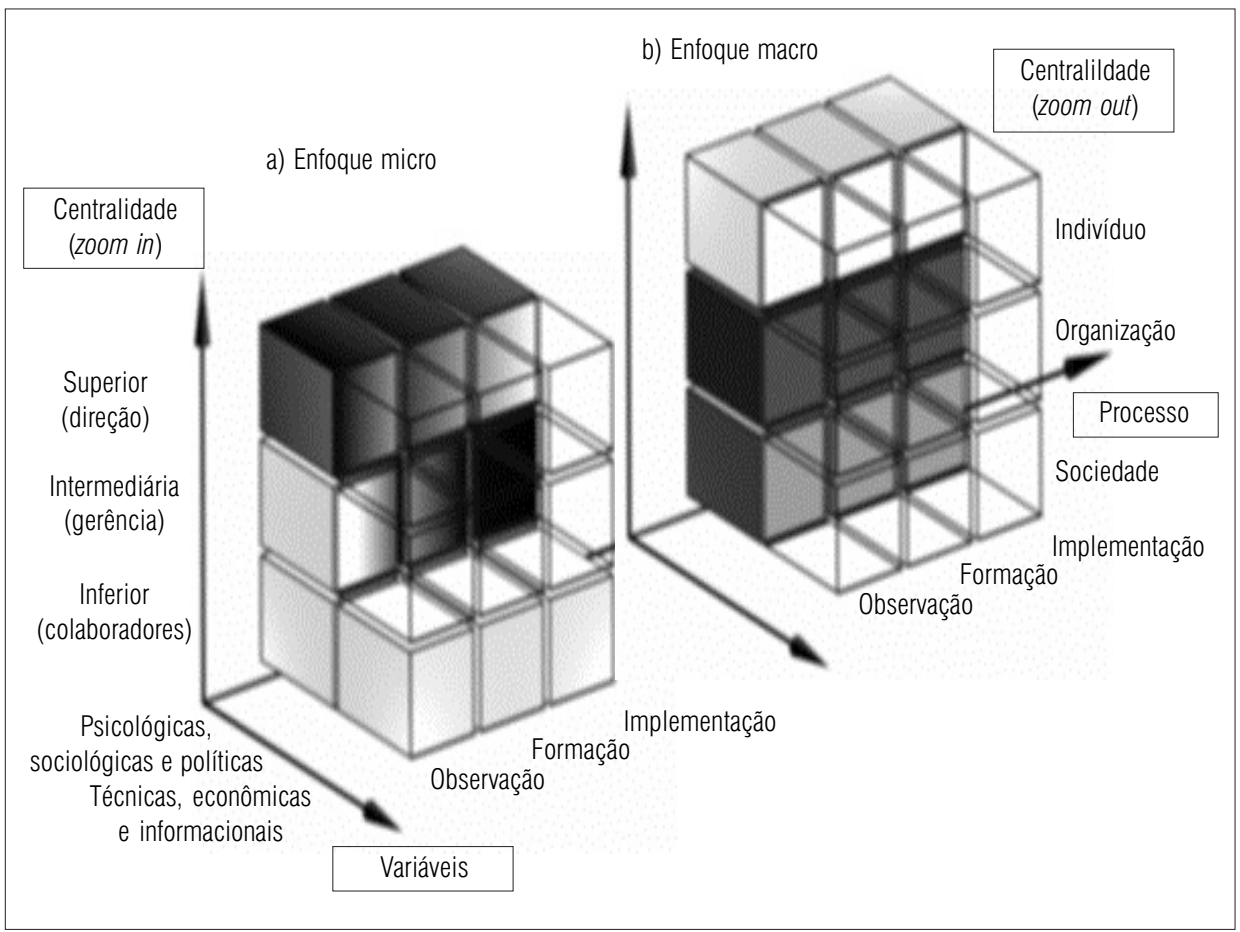

A vertente do poder macro, apesar de manter o foco nas mesmas variáveis intangíveis, baseia-se no poder das demandas externas (ambiente). Para os autores dessa vertente, a organização busca seus interesses pelo controle ou pela cooperação com outras organizações, por meio do uso de manobras estratégicas, portanto tendo seu foco no eixo da centralidade baseado nos espaços da organização e da sociedade em que ela se insere (onde estão seus demais stakeholders). Tais relações de poder para essa escola seriam importantes tanto na interpretação (observação) da organização e de seu ambiente, quanto na formação de suas estratégias (e sua conseqüente implementação). Para a escola do poder, portanto, o gestor deve estar atento ao lado político da formação das estratégias, tendo habilidade em lidar com interesses conflitantes 
e construir, dentro do processo de negociação, condições para o sucesso da organização. Astley (1984) figura entre os representantes da escola de poder dentro do enfoque macro.

\section{Escola cultural}

A principal premissa dessa escola é a idéia de que a formação da estratégia é um processo fundamentalmente de interação social, que por meio da aculturação gera conhecimento tácito, de modo que o conhecimento não codificável acumulado é mais importante e determinante nos rumos das organizações do que o proveniente do planejamento racional e deliberado. A estratégia derivaria, portanto, de intenções coletivas que podem se traduzir em barreiras e/ou facilitadores para determinadas escolhas. A escola vê a formação das estratégias como um processo deliberadamente emergente, trazendo a importante dimensão coletivista de um processo social, embora não discutindo sua implementação.

O gestor deve ter a capacidade de construir ou se utilizar da cultura organizacional. A estratégia, quando fortemente apoiada em aspectos culturais, seria de difícil imitação. Por outro lado, para gerar mudanças na estratégia, o gestor teria de ser capaz de promover mudanças na cultura existente, o que naturalmente implica processos de câmbio mais radicais, em função de competências essenciais estarem em jogo (Prahalad e Hamel, 1990). Nesse sentido, os autores filiados à corrente da visão baseada em recursos (RBV) ${ }^{5}$ podem ser enquadrados no âmbito da escola cultural, na medida em que se debruçam sobre as origens das capacidades dinâmicas (Teece, Pisano e Shuen, 1997) na evolução da cultura organizacional, diferindo da visão de Prahalad e Hamel, que enfatizam seu desenvolvimento por meio de um processo de aprendizado estratégico, conforme exposto em Mintzberg e outros (2000). A estratégia deve ser, na escola cultural, inserida no contexto histórico da organização.

A figura 12 ilustra a escola cultural e seu foco na sociedade, na organização e nos indivíduos que a compõem.

\footnotetext{
${ }^{5}$ É importante ressaltar que os avanços recentes da RBV (Makadok, 2001) estendem a atuação dessa tradição de pesquisa na direção das variáveis informacionais, na medida em que o novo foco passa a ser mais direcionado a auxiliar as organizações a resolverem seus problemas ligados a aquisição de informações do que colaborar no processo de formulação estratégica (Makadok e Barney, 2001). Nesse caso, a figura 12 seria alterada com um maior preenchimento das variáveis técnicas, econômicas e informacionais.
} 
Figura 12

Aplicação do modelo à escola cultural

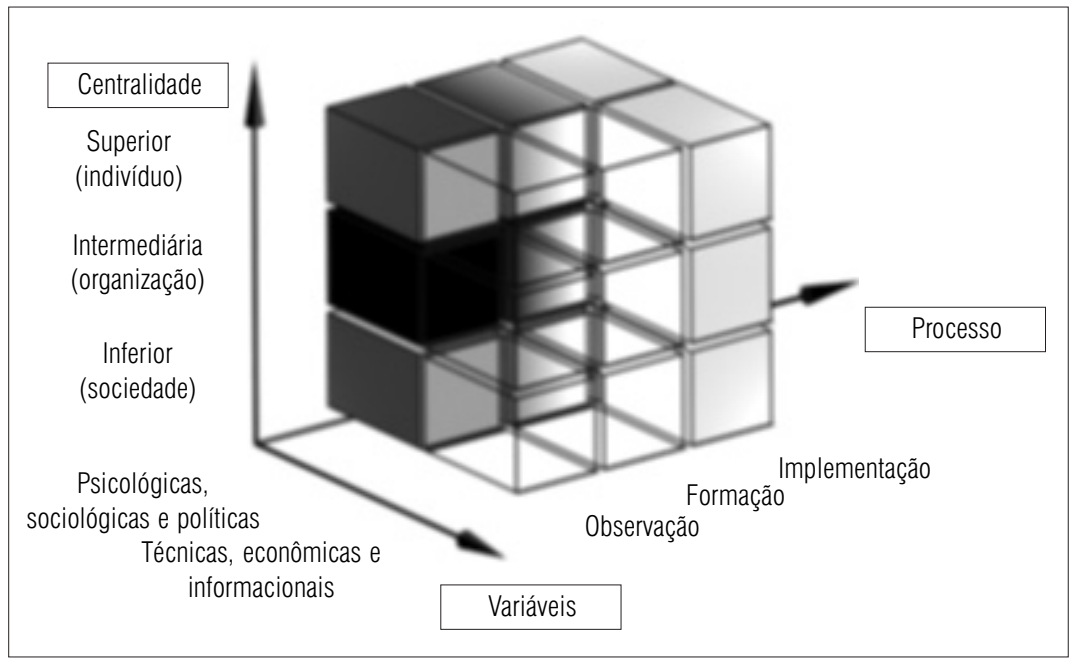

\section{Escola ambiental}

Autores dessa escola consideram as organizações passivas, podendo apenas reagir às mudanças em seu ambiente. Nesse caso, o ambiente ocupa, mesmo que pontualmente, papel preponderante no processo de formação estratégica, junto da liderança e da organização, condicionado às opções. Cabe à liderança a interpretação do ambiente de modo a garantir uma adaptação adequada da organização.

Com origens que remontam as teorias da contingência, Mintzberg e colaboradores (2000) dividem essa escola em duas facções. Os ecologistas de população (que eliminam a opção estratégica das organizações — ou elas fazem o que o ambiente "manda" ou serão eliminadas) e os teóricos institucionais (que acreditam que as pressões exercidas pelo ambiente reduzem a opção estratégica, mas não a eliminam). Dado que, conforme a percepção da escola, as pressões ambientais e as respectivas reações das organizações aconteceriam tanto por meio das variáveis tangíveis quanto das intangíveis, temos na figura 13 a representação da escola ambiental cobrindo todo o eixo do processo, enquanto no eixo da centralidade o mesmo se dá primariamente na sociedade e secundariamente na própria organização. 


\section{Aplicação do modelo à escola ambiental}

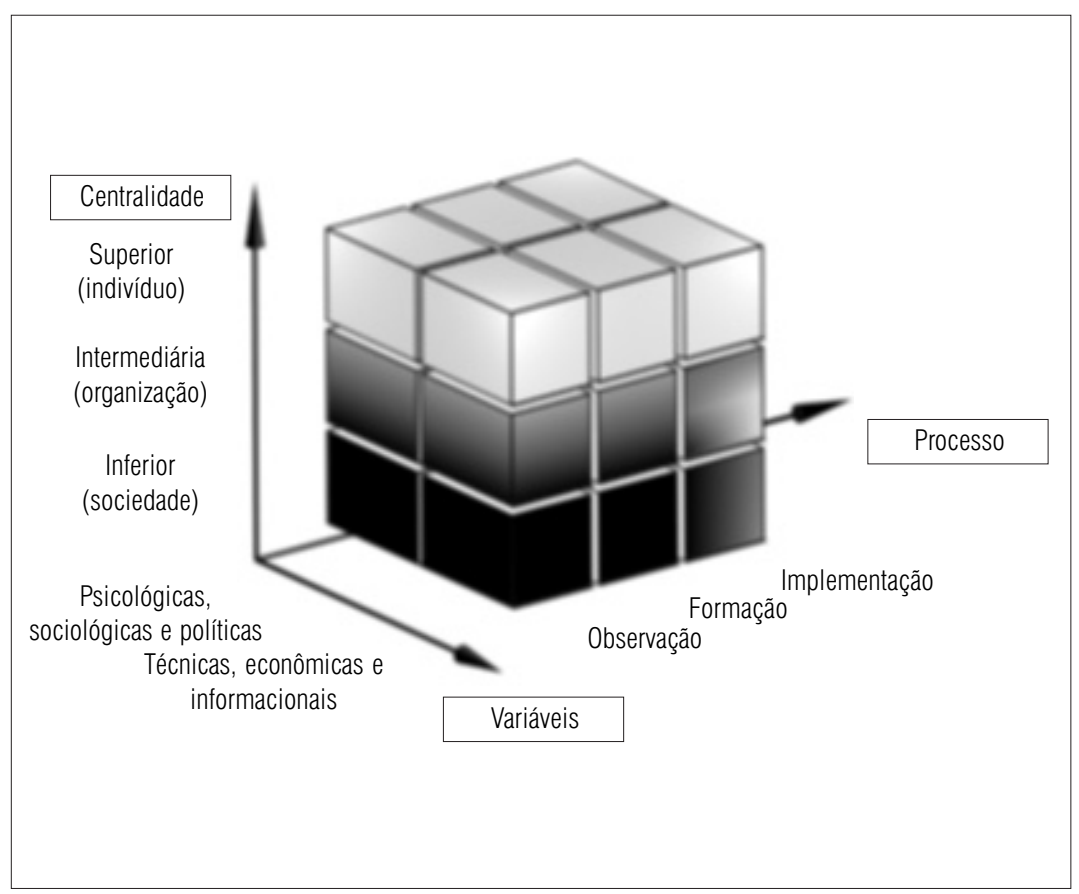

\section{Escola da configuração}

A última escola é caracterizada por seu caráter abrangente. Segundo os autores, para cada período ou situação de contexto a organização deveria adotar uma determinada forma de estrutura de formação de estratégias. Tais períodos (estáveis) alternar-se-iam eventualmente com mudanças para outras configurações (cada configuração explicada, em um momento, por uma das escolas anteriores). Os ciclos de vida das organizações seriam, portanto, caracterizados por estados de configuração intercalados por períodos de transformação e sua abrangência de foco cobriria todo o espaço analítico, superpondo as figuras 6 a 13 e resultando na figura 14. O próprio Mintzberg se apresenta como um representante dessa abordagem. 
Figura 14

\section{Aplicação do modelo à escola da configuração}

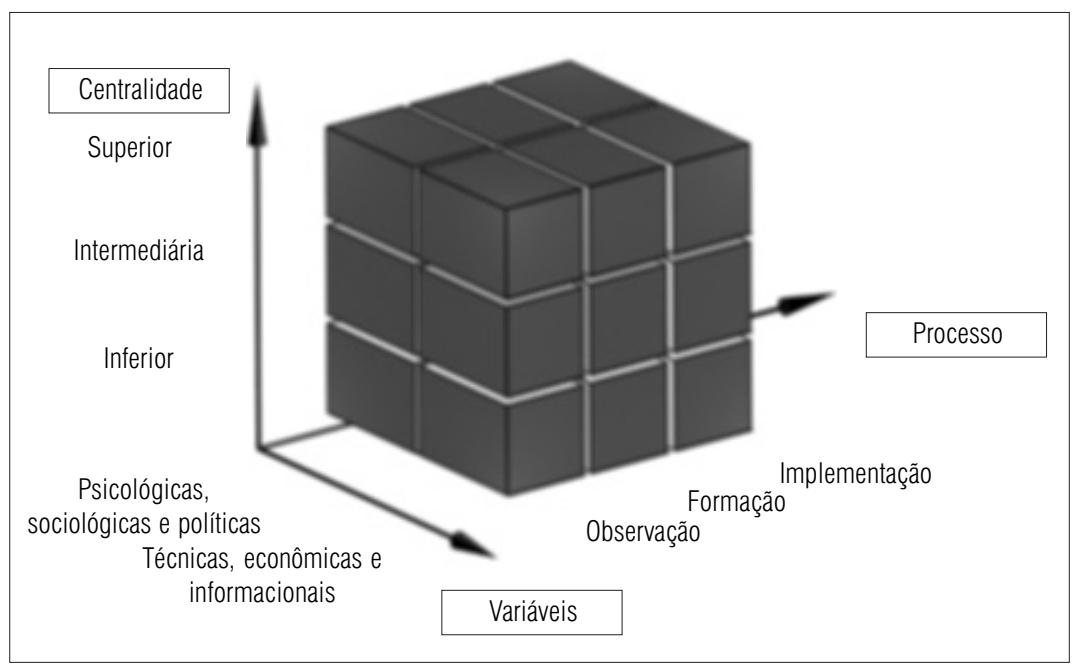

\section{Considerações finais}

Evidentemente, reconhecemos a existência de limitações quanto ao modelo e suas representações demonstradas. Os movimentos e posições de cada escola de pensamento poderiam ser mais bem explicados por meio de uma "viagem pelas sutis fronteiras entre elas existentes", o que em verdade restringe a tipificação estanque, tanto das 10 escolas focalizadas quanto de outras abordagens estratégicas passíveis de análise, tais como a abordagem de custos de transação. Nesse sentido, as próprias mudanças nas conexões entre estratégias e finanças (Kimura e Basso, 2007) podem alterar as percepções em relação ao posicionamento de cada escola no modelo espacial aqui apresentado.

Apesar das reconhecidas limitações do modelo proposto, entendemos porém que o mesmo pode ser útil na visualização e compreensão do problema estratégico das organizações, e certamente no ensino ${ }^{6}$ das escolas de pensamento estratégico, sejam elas as de Mintzberg, Ahlstrand e Lampel ou quaisquer outras.

\footnotetext{
${ }^{6}$ Em função de seu didatismo e potencial clareza de exposição/comparação de enfoques.
} 
Por fim, entendemos que o modelo presta-se também para explicar a polêmica entre Ansoff e Mintzberg citada no início deste artigo.

Em seu texto crítico, Mintzberg (1990) ataca fortemente a escola do design. Ansoff responde em 1991 afirmando literalmente que Mintzberg joga a escola do design na lata do lixo e que ele, Ansoff, tinha décadas de resultados práticos e positivos na aplicação de suas prescrições. Só que o trabalho de Mintzberg, Ahlstrand e Lampel (2000) posiciona Ansoff não na escola do design, mas na do planejamento. Assim, Igor teria se precipitado ao se sentir inserido diretamente naquela crítica.

Aplicando o modelo aqui apresentado às escolas do design e do planejamento, percebemos que a única interseção entre as duas (sob essa ótica) se dá nos quadrantes 2 (parcialmente) e 3 da figura 6. Dentro da escola do planejamento, era exatamente esse o espaço de maior foco de Ansoff, o que explica, ao menos parcialmente, por que este último sentiu-se atingido pelas críticas mencionadas.

\section{Referências bibliográficas}

ALLISON, G. Essence of decision: exploring the Cuban missile crisis. Boston: Little, Brown, 1971.

ANSOFF, I. H. Corporate strategy: an analytical approach to business policy for growth and expansion. New York: McGraw-Hill, 1965.

. From strategic planning to strategic management. London: John Wiley, 1976.

. Critique of Henry Mintzberg's the design school; reconsidering the basic premises of strategic management. Strategic Management Journal, v. 12, p. 449-461, 1991.

ASTLEY, W. G. Toward an appreciation of collective strategy. Academy of Management Review, v. 9, n. 3, p. 526-535, 1984.

CYERT, R.; MARCH, J. A behavioral theory of the firm. New Jersey: Prentice Hall, 1963.

DRUCKER, P. F. The practice of management. London: W. Heinemann, 1955.

GRANOVETTER, Marc. Economic action and social structure: the problem of embeddedness. American Journal of Sociology, v. 91, n. 3, p. 481-510, Nov. 1985.

KIMURA, H.; BASSO, L. Estratégia e finanças na dança dos famosos: pisando nos calos e sincronizando coreografias. In: ENANPAD, 31., Rio de Janeiro, 2007. Anais... Rio de Janeiro, 2007. 
MAKADOK, R. Toward a synthesis of the resource-based and dynamic capability views of rent-creation. Strategic Management Journal, v. 22, p. 387-401, 2001.

; BARNEY, J. Strategic factor market intelligence: an application of information economics to strategy formulation and competitor intelligence. Management Science, v. 47, n. 12, p. 1621-1638, Dec. 2001.

MINTZBERG, H. The design school: reconsidering the basic premises of strategic management. Strategic Management Journal, v. 11, p. 171-195, 1990.

.; AHLSTRAND, B; LAMPEL, J. Strategy safari. New York: Free Press, 2000.

; WATERS, J. A. Of strategies deliberate and emergent. In: DAVID, A.; BOWMAN, C. (Eds.). Readings on strategic management. London: McMillan, 1985.

PORTER, M. Competitive advantage: techniques for analyzing industries and competitors. New York: Free Press, 1980.

PRAHALAD, C. K.; HAMEL, G. The core competence of the corporation. Harvard Business Review, v. 68, n. 3, p. 79-91, May 1990.

QUINTELLA, R. H. The strategic management of technology in the chemical and petrochemical industries. London: Pinter, 1993.

; DIAS, C. C. Trends in international business thought and literature: business strategy in Brazil. The International Executive. Glendale: Wiley, v. 3, n. 39, p. 433-458, 1997.

SCHUMPETER, J. Capitalismo, socialismo e democracia. Rio de Janeiro: Zahar, 1984.

SELZNICK, P. Leadership in administration. Illinois: Evanston, 1957.

SIMON, H. A. Administrative behavior. New York: Macmillan, 1947.

SKINNER, W. Manufacturing - missing link in corporate strategy. Harvard Business Review, v. 47, n. $3,1969$.

TEECE, D.; PISANO, G.; SHUEN, A. Dynamic capabilities and strategic management. Strategic Management Journal, v. 18, n. 7, p. 509-534, 1997.

TREGOE, B.; ZIMMERMAN, J. A estratégia da alta gerência. Rio de Janeiro: Zahar, 1980.

VASCONCELOS, F. Safári de estratégia, questões bizantinas e a síndrome do ornitorrinco: uma análise empírica dos impactos da diversidade teórica em estratégia empresarial sobre a prática dos processos de tomada de decisão estratégica. In: ANPAD 2001. Campinas, 2001. Anais... Campinas, 2001. 1CD. 